\title{
Paradoxes of Exile: Place and Displacement in the Poetry of Derek Mahon
}

\author{
Dr. Hend Hamed Ezzeldin
}

\begin{abstract}
:
Exile is not a singular phenomenon but rather a varied and a heterogeneous one. The term exile generally denotes displacement which refers to a movement out of one's original place, be it imposed or by one's choice. The theme of exile is pervasive in Irish literature reflecting the isolation felt by Irish writers who regarded themselves homeless at home and uprooted from earth as a whole. Many critics maintained that this intense sense of un-belonging to any place is translated into the logic of 'colonial aphasia' from Derek Mahon whose poetry is conditioned by various types of exile. Failing to take a stance of what was happening in his homeland and to elucidate his cantankerous, dissociated feelings, Mahon's decision was to sever himself entirely from any home no matter what this 'home' incarnates. In one of his interviews, however, Derek Mahon expressed utter disapproval of being seen as an exile and made it explicit that this should not be the way to interrogate his writing. Despite the fact that much of his poetry testifies that he is a displaced writer in exile, deeper readings of his works would showcase various attempts at connecting with the world he seems to reject. This paper attempts to examine Mahon's occult sentiments towards his homeland, his people, and his vocation by delving into some of his major poems to illustrate his endeavors at association even if the poems reflect detachment and disconnection. In every poem, there is a sense of belonging - to a place, a people, or to one's self - despite the sweeping motifs of division and aloofness.
\end{abstract}

\section{Key words}

Exile - displacement - Irish - modernity - Mahon 